\title{
Structure of inositol monophosphatase, the putative target of lithium therapy
}

\author{
Roger Bone*†, James P. Springer*, AND John R. ATACK \\ *Department of Biophysical Chemistry, Merck Research Laboratories, P.O. Box 2000, Rahway, NJ 07065; and $\ddagger$ Merck Research Laboratories, Neurosciences \\ Research Center, Terlings Park, Eastwick Road, Harlow, Essex, CM20 2QR, United Kingdom
}

Communicated by Philip W. Majerus, July 27, 1992

\begin{abstract}
Inositol monophosphatase (EC 3.1.3.25), the putative molecular site of action of lithium therapy for manicdepressive illness, plays a key role in the phosphatidylinositol signaling pathway by catalyzing the hydrolysis of inositol monophosphates. To provide a structural basis from which to design better therapeutic agents for manic-depressive illness, the structure of human inositol monophosphatase has been determined to 2.1- $\AA$ resolution by using $x$-ray crystallography. The enzyme exists as a dimer of identical subunits, each folded into a five-layered sandwich of three pairs of $\alpha$-helices and two $\boldsymbol{\beta}$-sheets. Sulfate and an inhibitory lanthanide cation $\left(\mathbf{G d}^{3+}\right)$ are bound at identical sites on each subunit and establish the positions of the active sites. Each site is located in a large hydrophilic cavern that is at the base of the two central helices where several segments of secondary structure intersect. Comparison of the phosphatase aligned sequences of several diverse genes with the phosphatase structure suggests that the products of these genes and the phosphatase form a structural family with a conserved metal binding site.
\end{abstract}

Lithium therapy for manic-depressive illness is believed to be effective because of the ability of $\mathrm{Li}^{+}$to reduce signal transduction through the phosphatidylinositol signaling pathway (1-5). In this pathway second messengers diacylglycerol and inositol trisphosphate are produced from phosphatidylinositol-4,5-bisphosphate by the receptor-mediated activation of phosphatidylinositol-specific phospholipase C (1). Metabolism of inositol-1,4,5-trisphosphate, which induces the release of $\mathrm{Ca}^{2+}$ from internal stores, to inositol, a precursor for the resynthesis of inositol lipids, involves several hydrolytic steps $(1,6)$. Uncompetitive $\mathrm{Li}^{+}$inhibition of two $\mathbf{M g}^{2+}$-dependent phosphatases in the signaling pathway, inositol monophosphatase (EC 3.1.3.25) (5) and inositol polyphosphate 1-phosphatase (refs. 7 and 8; also designated inositol-1,3,4-trisphosphate/inositol-1,4-bisphosphate 1-phosphatase, ref. 9), reduces the pool of inositol available for the resynthesis of inositol phospholipids, thereby reducing the phosphatidylinositol-specific phospholipase C-mediated production of second messengers $(1,2)$. The effects of $\mathrm{Li}^{+}$on manic-depressive illness are surprisingly specific, in part because of the inability of inositol to cross the bloodbrain barrier and replenish depleted inositol levels but also because of the uncompetitive $\mathrm{Li}^{+}$inhibition $(1,2)$, which exerts the greatest influence when substrate is saturating (10). Because inositol monophosphatase is responsible for catalyzing the hydrolysis of inositol monophosphates produced both in the signaling pathway and in the de novo biosynthesis of inositol from glucose 6-phosphate, it appears to be the most plausible molecular site of action of $\mathrm{Li}^{+}(1,2)$. As a first step toward the goal of using the atomic structure of the enzyme to design inhibitors, the crystal structure of human inositol monophosphatase, a dimer of identical 277-amino

The publication costs of this article were defrayed in part by page charge payment. This article must therefore be hereby marked "advertisement" in accordance with 18 U.S.C. $\$ 1734$ solely to indicate this fact. acid subunits ( $30 \mathrm{kDa}$; ref. 11$)$ has been determined to $2.1-\AA$ resolution. $\$$

\section{EXPERIMENTAL PROCEDURES}

Materials. Cloned human inositol monophosphatase was purified from Escherichia coli as described (11) and crystallized by vapor diffusion (12). Because inositol monophosphatase is inhibited by $\mathrm{Ca}^{2+}(5)$, crystallization experiments were attempted in the presence of both $\mathrm{Ca}^{2+}$ and $\mathrm{Gd}^{3+}$, a heavy metal substitute for $\mathrm{Ca}^{2+}(13)$. Hanging drops were prepared by adding equal volumes (2-4 $\mu$ l) of solutions of 64-68\% saturated $\mathrm{Li}_{2} \mathrm{SO}_{4}$ (Fluka; adjusted to $\mathrm{pH} 7.0$ ) containing $5 \mathrm{mM}$ glutathione, $3 \mathrm{mM} \mathrm{NaN}_{3}$, and either 2-6 mM $\mathrm{Gd}_{2}\left(\mathrm{SO}_{4}\right)_{3}$ (Aldrich) or $5 \mathrm{mM} \mathrm{CaSO}{ }_{4}$ and of inositol monophosphatase $(10 \mathrm{mg} / \mathrm{ml})$ containing $20 \mathrm{mM}$ Tris $\cdot \mathrm{HCl}(\mathrm{pH} 7.8)$, $1 \mathrm{mM}$ EGTA, and $2 \mathrm{mM} o$-phenanthroline and allowing the drops to equilibrate for several weeks. Cylinders with a hexagonal cross section formed within 3 days in the presence of $\mathrm{Gd}^{3+}$ and within 2 months in the presence of $\mathrm{Ca}^{2+}$.

Data Collection. Native and derivative data were collected from single crystals by using monochromatic $\mathrm{CuK}_{\alpha} \mathrm{x}$-rays $(\lambda$ $=1.5418 \AA$ ) and a Siemens multiwire $\mathrm{x}$-ray area detector. Data were processed by using Version 2.0 of the XENGEN software (14). To optimize the accuracy of the observation of anomalous scattering for the $\mathrm{Gd}^{3+}$ derivative, data sets $(d>$ $2.6 \AA)$ were collected in complementary $\omega$ scans, one starting at the angles $\phi, \chi, \omega$, and $2 \theta$ and collecting frames with an oscillation of $+\Delta \omega$ and the second starting at the angles $\phi, \chi$, $-\omega$, and $-2 \theta$ and collecting frames with an oscillation of $-\Delta \omega$. Values of $\Delta F$ for the Friedel pairs of the $G^{3+}$ derivative were calculated using data that had been reduced without merging the Friedel pairs. For refinement of the structure of the $\mathrm{Gd}^{3+}$ complex, higher-resolution data were collected from a second $\mathrm{Gd}^{3+}$ crystal and merged with data from the first crystal, with the data from each crystal reduced with the Friedel pairs merged.

Structure Solution. Precession photography and intensity data indicated the space group was either $P 3_{2} 21$ or $P 3_{1} 21$ with cell dimensions $a=b=86.2 \AA$ and $c=154.3 \AA$. The solvent content was estimated (15) to be $55 \%$ on the basis of the unit cell volume and the assumption that the asymmetric unit of the crystal was a phosphatase dimer $(60 \mathrm{kDa})$. Difference Patterson maps, calculated using observed structure factors from $\mathrm{Ca}^{2+}$ and $\mathrm{Gd}^{3+}$ crystals of the phosphatase, clearly revealed two high-occupancy metal binding sites. An anomalous difference Patterson map was calculated using filtered structure factors (16) from the $\mathrm{Gd}^{3+}$ crystal and yielded the same two sites. The presence of two metal binding sites was consistent with the hypothesis that the asymmetric unit was composed of an inositol monophosphatase dimer.

†To whom reprint requests should be addressed.

8The atomic coordinates and structure factors have been deposited in the Protein Data Bank, Chemistry Department, Brookhaven National Laboratory, Upton, NY 11973 (reference ID code 1HHM) and will be available for distribution after January 1993. 
Heavy atom refinement was performed with the program TCTREF (17) as modified and enhanced by V. Ramalingam (personal communication) using only the isomorphous differences and pseudo scattering factors to represent the electron difference between $\mathrm{Ca}^{2+}$ and $\mathrm{Gd}^{3+}$. Initial phases were calculated from the native and derivative data using the refined heavy atom parameters and from the differences between Friedel pairs in the derivative data using the scattering factors for $\mathrm{Gd}^{3+}$. Electron density maps were calculated using these phases and indicated that $P 3_{2} 21$ was the correct space group and provided an outline of the protein and some structural details.

A mercury derivative was produced by soaking a crystal grown in the presence of $\mathrm{Gd}^{3+}$ with $2 \mathrm{mM}$ sodium mersalate, added in a solution containing $75 \%$ saturated $\mathrm{Li}_{2} \mathrm{SO}_{4}, 2.5 \mathrm{mM}$ $\mathrm{Gd}_{2}\left(\mathrm{SO}_{4}\right)_{3}$, and $20 \mathrm{mM}$ Tris buffer adjusted to $\mathrm{pH} 7.1$. The heavy-atom structure of the mersalyl and $\mathrm{Gd}^{3+}$ derivative could not be determined from a difference Patterson map, although the known $\mathrm{Gd}^{3+}$ sites were evident in an anomalous difference Patterson map. However, a difference electron density map, calculated using native $\left(\mathrm{Ca}^{2+}\right)$ and derivative (mersalate $/ \mathrm{Gd}^{3+}$ ) structure factors and preliminary phases from the isomorphous $\mathrm{Gd}^{3+}$ derivative after solvent flattening (18) revealed the two $\mathrm{Gd}^{3+}$ sites, $12 \mathrm{Hg}$ sites at various occupancies, and the noncrystallographic symmetry between the two phosphatase subunits. Heavy-atom positions and occupancies were refined using TCTREF (17) as modified and enhanced by V. Ramalingam (personal communication) with the noncrystallographic symmetry constraint and new phases were calculated. These phases were improved using solvent flattening $(18,19)$ and the resulting electron density map was averaged using noncrystallographic symmetry (20).

The program FRODO (21) was used to build the protein chain into the electron density map and the structure was refined using PROLSQ $(22,23)$, treating the subunits as independent protein segments throughout refinement. The model was refined using data from the $\mathrm{Gd}^{3+}$ crystals because of the inability to grow large $\mathrm{Ca}^{2+}$ crystals. Approximately $10 \%$ of the residues appeared to be disordered and were either left out of the model, including the $\mathrm{N}$-terminal three residues and C-terminal residue, or refined as multiple conformations. In three regions having the highest temperature factors in the protein, residues $29-33,75-80$, and $275-276$, some disorder is still apparent and the model remains somewhat uncertain. Electron density supporting the model returns in these regions in omit maps calculated using coordinates that had been refined for three cycles with up to 15 residues of the chain removed. The final model, with a crystallographic residual error $(R)$ value of 0.166 (Table 1 ), includes two protein chains of 273 residues, two $\mathrm{Gd}^{3+}$ atoms, two metal-bound sulfates, and 239 water molecules and has an average temperature factor of $26 \AA^{2}$.

\section{RESULTS}

Structure. Inositol monophosphatase is an $\alpha-\beta$ protein with a five-layered sandwich of $\alpha$-helices and $\beta$-sheets for each subunit (Fig. 1A). In each phosphatase subunit, a central pair of helices are flanked by two $\beta$-sheets, both largely antiparallel, that together make up a central core. This core is flanked on each side by two additional pairs of helices, establishing a sandwich of alternating pairs of helices and $\beta$-sheet structures $(\alpha \cdot \beta \cdot \alpha \cdot \beta \cdot \alpha)$. The structure is completed by two small helices, approximately two turns each, and several extended or irregular segments of protein chain. The subunit interface is extensive and involves interactions distributed throughout the chain (Fig. $1 B$ ): $10 \%$ of the surface area on each subunit is buried upon dimer formation $\left(1200 \AA^{2}\right.$; roughly two-thirds nonpolar atoms) and $17 \%$ of the residues on each subunit are close enough to participate in the
Table 1. Statistics for structure determination

\begin{tabular}{|c|c|c|c|}
\hline Parameter & $\begin{array}{l}\text { Native } \\
\left(\mathrm{Ca}^{2+}\right)\end{array}$ & $\mathrm{Gd}^{3+}$ & $\begin{array}{c}\mathrm{Gd}^{3+} / \\
\text { mersalate }\end{array}$ \\
\hline \multicolumn{4}{|l|}{ Diffraction data } \\
\hline Resolution, $\AA$ & 2.60 & 2.10 & 3.00 \\
\hline Crystals, no. & 1 & 2 & 1 \\
\hline Total observations, no. & 64,631 & 167,162 & 50,419 \\
\hline Unique observations, no. & 19,468 & 34,469 & 12,689 \\
\hline Completeness, $\%$ & 93.3 & 98.2 & 93.0 \\
\hline$\left\langle\mathbf{I} / \sigma_{\mathbf{I}}\right\rangle$ & 21.1 & 24.1 & 10.1 \\
\hline$R_{\text {merge }}$ & 0.064 & $0.059 / 0.097$ & 0.075 \\
\hline \multicolumn{4}{|l|}{ Phasing } \\
\hline Heavy atom sites, no. & & 2 & 14 \\
\hline Isomorphous differences, no. & & 14,871 & 10,311 \\
\hline Anamolous differences, no. & & 9,690 & - \\
\hline rms $\boldsymbol{F}_{\mathrm{H}} /$ residual & & 0.90 & 1.27 \\
\hline$R_{\text {Cullis }}$ & & 0.64 & 0.57 \\
\hline $\boldsymbol{R}_{\text {anom }}$ & \multirow{2}{*}{\multicolumn{3}{|c|}{0.52}} \\
\hline$\langle$ Figure of merit $\rangle$ & & & \\
\hline $\begin{array}{l}\langle\text { Figure of merit }\rangle \text { after } \\
\text { solvent flattening }\end{array}$ & \multirow{2}{*}{\multicolumn{3}{|c|}{0.81}} \\
\hline Refinement & & & \\
\hline $\boldsymbol{R}_{\text {cryst }}$ & & 0.166 & \\
\hline Protein atoms, no. & & 4,044 & \\
\hline Metal cations, no. & & 2 & \\
\hline Sulfates, no. & & 2 & \\
\hline $\begin{array}{l}\text { Waters, no. } \\
\text { rms deviations from ideal }\end{array}$ & & 239 & \\
\hline Bond lengths, $\AA$ & & 0.018 & \\
\hline Angles, degrees & & 1.5 & \\
\hline
\end{tabular}

$R_{\text {merge }}=\left[\Sigma \Sigma\left|I_{j}(h)-\langle I(\mathrm{~h})\rangle\right| /\left(\Sigma \Sigma I_{j}(h)\right] ;\right.$ summations done over all reflections from a crystal. rms $F_{\mathrm{H}} /$ residual = phasing power, where $F_{H}$ is the rms calculated heavy atom structure factor and residual is the rms lack of closure error. $R_{\text {Cullis }}=\left(\Sigma\left|F H_{\text {calc }}-F_{\text {obs }}\right|\right) /(\Sigma$ $\left.\left|F_{P H} H_{\text {obs }}-\mathrm{FP}\right|\right)$; for centric reflections only, where FPH is the derivative structure factor and FP is the native structure factor. rms $\boldsymbol{R}_{\text {anom }}=\mathrm{rms}$ phase averaged anomalous residual divided by the rms observed anomalous difference. $R_{\text {cryst }}=\left(\Sigma\left|F_{\text {obs }}-F_{\text {calc }}\right|\right) /\left(\Sigma\left|F_{\text {obs }}\right|\right)$.

exclusion of solvent from the interface $(25,26)$. The dimer is further stabilized by the formation of 18 hydrogen bonds (donors or acceptors within $3.3 \AA$ of partners) between the subunits. When the two subunits are aligned, the root mean square deviation between all $\alpha$ carbons is $0.26 \AA$, indicating that the core structures of the subunits are almost identical. Significant deviations between the main-chain structures of the subunits, with root mean square deviations up to $1 \AA$, occur only in turns and solvent-exposed, extended, or irregular segments of the chain. Differences in the side-chain conformations on each subunit are more prevalent than main-chain differences but also appear restricted to solventexposed residues.

Active Site. The two active sites are identified by the locations of the $\mathrm{Gd}^{3+}$ atoms, since $\mathrm{Gd}^{3+}$ and $\mathrm{Ca}^{2+}$ bind at the same site and because $\mathrm{Ca}^{2+}$ is a competitive inhibitor with respect to $\mathbf{M g}^{2+}(5)$. In addition, sulfate molecules are bound to the $\mathrm{Gd}^{3+}$ on each subunit and would be expected to interact with the enzyme in the essentially same manner as the phosphate group of substrates or phosphate product. Some penetration of residues from the $B$ subunit into the active site of the A subunit is observed, but it does not appear that the active site is shared between subunits. In particular, Arg-191 projects through the subunit interface and interacts with the solvent filling the active site, but remains a distance of $11 \AA$ from the metal binding site. The active site caverns are surprisingly large and hydrophilic, apparently much larger than would be required to accommodate inositol monophosphate. In addition to the sulfate and cation, $\approx 30$ molecules of solvent fill the active site caverns and slightly $>50 \%$ of the 

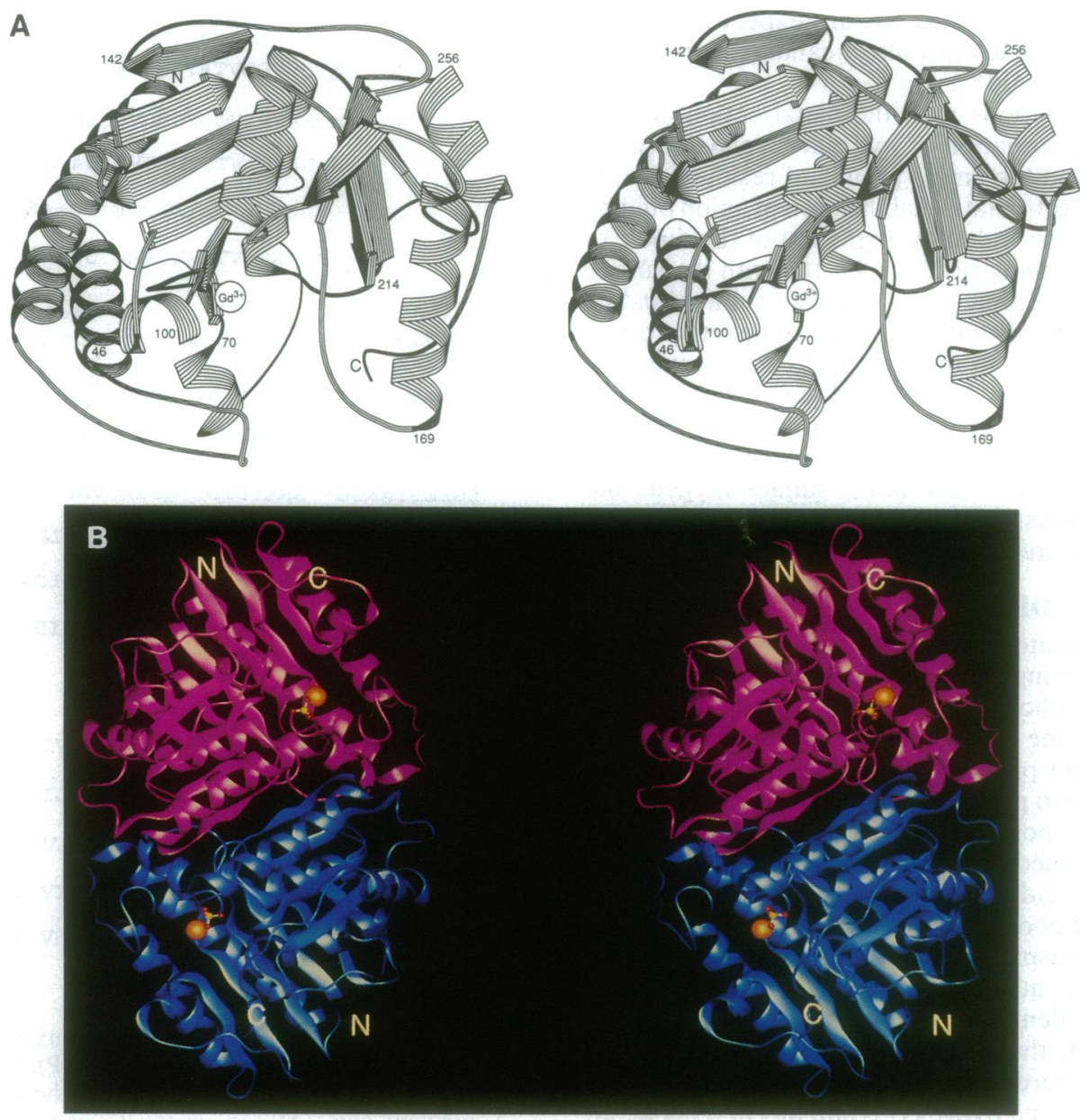

FIG. 1. Stereo drawings of stylized ribbon representations of the secondary structure of the inositol monophosphatase monomer (A) (24) and dimer $(B)$. The view of the monomer is into the subunit interface of the molecule and the active site is identified by the $\mathrm{Gd}^{3+}$. The view of the dimer is approximately down the dimer twofold axis and shows the locations of sulfate (ball and stick) and $\mathrm{Gd}^{3+}$ (orange sphere).

surface of the active site is contributed by polar atoms with no large hydrophobic patches evident.

Within $3 \AA$ of the metal cation on each subunit are nine atoms that are possible metal ligands, including both carboxylate oxygens of Asp-90 (2.38 $\AA$ and $2.95 \AA)$, the carbonyl oxygen of Ile-92 (2.44 $\AA$ ), the hydroxyl group of Thr-95 (2.80 $\AA)$, one carboxylate oxygen of Glu-70 $(2.50 \AA)$, two oxygens of the bound sulfate ( $2.59 \AA)$, and two molecules of water (2.62 $\AA$ and $2.61 \AA$; Fig. 2). Residues 90-95, which contribute

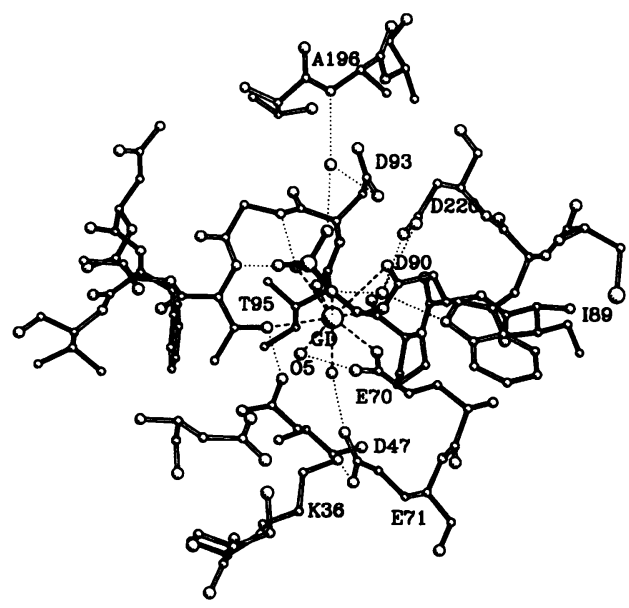

four of the metal ligands, form an unusual kinked structure that wraps around the metal. These metal-ligand distances were unrestrained during refinement and the mean distance is $2.63 \AA$. The sum of the ionic radius for nine coordinate $\mathrm{Gd}^{3+}$ and the van der Waals radius for oxygen is $\approx 2.7 \AA$, so atoms further than $2.7 \AA$ from the metal cation, including one carboxylate oxygen of Asp-90 and Thr-95 and one of the sulfate oxygens, may be questionable as ligands. Although lanthanide cations commonly have as many as eight or nine

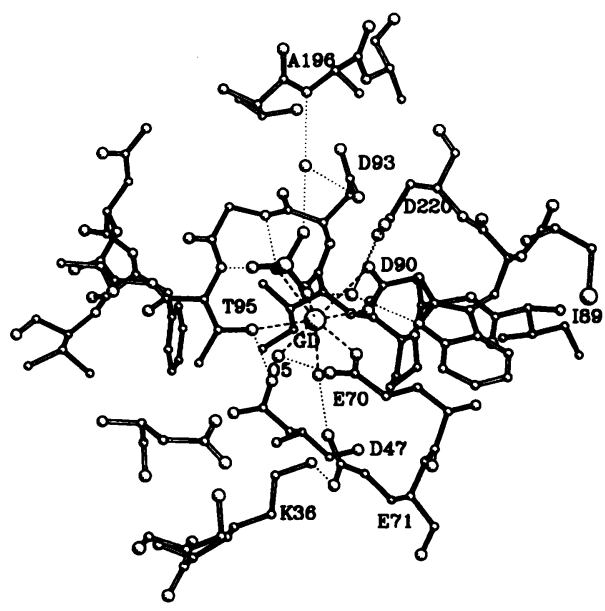

Fig. 2. Stereo drawing of the inositol monophosphatase active site showing the residues involved in $\mathrm{Gd}^{3+}$ and sulfate (solid bonds) binding. Possible intermolecular hydrogen bonds are indicated by dotted lines and possible coordinate bonds are indicated by dashed lines. 
coordinating ligands, only six ligands are expected to coordinate to $\mathrm{Mg}^{2+}(27)$ with the most likely candidates being the six atoms closest to the $\mathrm{Gd}^{3+}$.

In addition to interactions with the metal cation, sulfate binding involves the formation of hydrogen bonds between one sulfate oxygen and the amide groups of residues 94 and 95 (Fig. 2). Further electrostatic stabilization of anion binding to the protein may be provided by alignment of the dipole of the two-turn helix spanning residues $95-100$ with the sulfate oxygen. Two water molecules also stabilize sulfate binding by forming hydrogen bonds with both the sulfate and protein, one by hydrogen bonding to the sulfate 01 , carboxylate of Asp-93, and amide group of Ala-196 and the other by hydrogen bonding to the sulfate $\mathrm{O} 3$ and side chains of Asp-220 and Trp-219. Asp-93 and Asp-220 are within hydrogen bonding distance of each other and of one of the sulfate oxygens and would be expected to destabilize sulfate binding unless one of the residues is protonated.

\section{DISCUSSION}

Studies of bovine inositol monophosphatase have not provided evidence to distinguish unequivocally between alternate mechanisms of phosphate hydrolysis involving either the attack of an enzyme nucleophile or the direct attack of water on the substrate phosphoryl group (28-33). Interpretation of the structure to provide definitive support for one of the mechanisms is not possible due to the difference in metal coordination that is expected when the normal cofactor $\mathbf{M g}^{2+}$ is bound rather than $\mathrm{Gd}^{3+}$. Furthermore, sulfate $\left(K_{\mathrm{i}}=17\right.$ $\mathrm{mM}$; ref. 5) may not coordinate to the metal in exactly the same manner as phosphate $\left(K_{i}=0.5 \mathrm{mM}\right.$; ref. 28$)$ or substrate. With these qualifications in mind, two possible nucleophiles can be identified based on the hypothesis that sulfate interacts with the enzyme in the same manner as phosphate: a metal-coordinated water molecule (Fig. 2, 05) and the metal-coordinated hydroxyl group of Thr-95 (Fig. 2). Of the two possibilities, the water is closer to the sulfate and in a more appropriate location to act as the active site nucleophile. The closest histidine or serine residues are located a distance of $>8 \AA$ from the sulfate sulfur and are poorly positioned relative to the metal binding site to function as nucleophiles. Although the structure of the phosphatase can not unambiguously resolve questions concerning the mechanism, it does provide a framework from which experiments can be designed to improve our understanding of the function of the phosphatase.

Recently, sequence similarity has been noted between inositol monophosphatase and the inferred products of several diverse genes $(29,34)$ including the products of the suhB and $a m t A$ genes of $E$. coli, the qa-x gene of Neurospora crassa, and the qut $G$ gene of Aspergillus nidulans. Based on the homology with inositol monophosphatase and evidence implicating these genes in the regulation of cellular processes (35-39), it was suggested that these genes act by enhancing the synthesis or degradation of phosphorylated messenger molecules (34). In mapping the aligned sequences of these genes onto the phosphatase structure, patterns of residue hydrophobicity are maintained in the structural core while insertions and more dramatic sequence variations occur in irregular segments, turns, or solvent-exposed residues. Very striking is the observation that residues from which the metal and phosphate binding sites are formed (see Fig. 2) are conserved in the sequences of these diverse genes (Fig. 3). From these observations it appears that the phosphatase, suhB, amtA, qa-x, and qutG are members of a structural family and have a conserved metal binding site. In addition, the possibility that the products of $\operatorname{suhB}, a m t A, q a-x$, and qut $G$ have phosphatase activities (34) is strengthened.

Inositol polyphosphate 1-phosphatase, the other enzyme in the phosphatidylinositol signaling pathway that is inhibited by

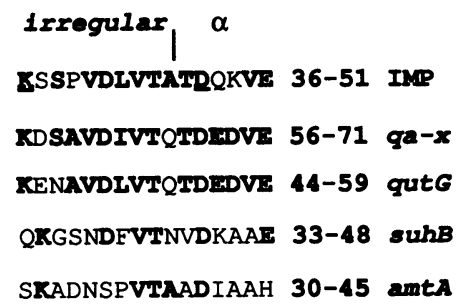

Fig. 3. Alignment (34) of two segments of the protein sequences of human inositol monophosphatase (IMP), the inferred products of $E$. coli genes suhB (35) and amtA (36), the $N$. crassa qa-x (37) and $A$. nidulans qut $G(40)$ gene products, and bovine inositol polyphosphate 1-phosphatase (IPP; ref. 8). Features of the inositol monophosphatase structure are mapped onto the phosphatase sequence and monophosphatase active site residues that may have functional roles are underlined. Conserved residues are in boldface type; residues involved in metal or sulfate binding are underlined.

$\mathrm{Li}^{+}$, has also been cloned (bovine), sequenced, and expressed in $E$. coli (8). Although the enzyme appears to have no overall sequence homology with inositol monophosphatase, an alignment of the two protein sequences is possible in two regions (Fig. 3 and refs. 8 and 34). Intriguingly, these regions include most of the residues from which the metal and phosphate binding sites of the monophosphatase are constructed. Uncompetitive inhibition of both enzymes by $\mathrm{Li}^{+}$and the possibility that the enzymes have the same metal/phosphate binding site suggests that $\mathrm{Li}^{+}$binding involves components of this site. Unfortunately, $\mathrm{Li}^{+}$is virtually invisible in an $\mathrm{x}$-ray crystallographic experiment because it has only two electrons. In addition, because $\mathrm{Li}^{+}$is an uncompetitive inhibitor, a substrate, product, or reaction intermediate (should any exist) is required for $\mathrm{Li}^{+}$binding. Therefore, the $\mathrm{Li}^{+}$binding site will remain uncertain unless the species to which $\mathrm{Li}^{+}$binds can be identified unambiguously. Fortunately, meeting the challenge of using the atomic structure of inositol monophosphatase to design inhibitors of the phosphatase that affect signal transduction in the same manner as $\mathrm{Li}^{+}$may not require identifying or utilizing the $\mathrm{Li}^{+}$binding site.

We thank Drs. J. W. Becker, P. M. D. Fitzgerald, B. McKeever, and C. I. Ragan for reviewing the manuscript and Dr. C. I. Ragan for his enthusiastic support of the inositol monophosphatase program.

1. Berridge, M. J. \& Irvine, R. F. (1989) Nature (London) 341, 197-205. 
2. Berridge, M. J., Downes, C. P. \& Hanley, M. R. (1989) Cell 59, 411-419.

3. Sherman, W. R., Gish, B. G., Honchar, M. P. \& Munsell, L. Y. (1986) Fed. Proc. Fed. Am. Soc. Exp. Biol. 45, 26392646.

4. Berridge, M. J., Downes, C. P. \& Hanley, M. R. (1982) Biochem. J. 206, 587-595.

5. Hallcher, L. R. \& Sherman, W. R. (1980) J. Biol. Chem. 255, 10896-10901.

6. Majerus, P. W., Connoly, T. M., Bansal, V. S., Inhorn, R. C., Ross, T. S. \& Lips, D. L. (1988) J. Biol. Chem. 263, 3051-3054.

7. Inhorn, R. C. \& Majerus, P. W. (1987) J. Biol. Chem. 262, 15946-15952.

8. York, J. D. \& Majerus, P. W. (1990) Proc. Natl. Acad. Sci. USA 87, 9548-9552.

9. Gee, N. S., Reid, G. G., Jackson, R. G., Barnaby, R. J. \& Ragan, C. I. (1988) Biochem. J. 253, 777-782.

10. Nahorski, S. R., Ragan, C. I. \& Challiss, R. A. J. (1991) Trends Pharmacol. Sci. 12, 297-303.

11. McAllister, G., Whiting, P., Hammond, E. A., Knowles, M. R., Atack, J. R., Bailey, F. J., Maigetter, R. \& Ragan, C. I. (1992) Biochem. J. 284, 749-754.

12. Felhammer, H. \& Bode, W. (1975) J. Mol. Biol. 98, 683-692.

13. Colman, P. M., Weaver, L. H. \& Matthews, B. W. (1972) Biochem. Biophys. Res. Commun. 46, 1999-2005.

14. Howard, A. J., Gilliland, G. L., Finzel, B. C., Poulos, T. L., Ohlendorf, D. H. \& Selemme, F. R. (1987) Acta Crystallogr. Sec. A 20, 383-387.

15. Matthews, B. W. (1968) J. Mol. Biol. 33, 491-496.

16. Hendrickson, W. A., Smith, J. L. \& Sheriff, S. (1985) Methods Enzymol. 115, 41-55.

17. Terwilliger, T. C. \& Eisenberg, D. (1983) Acta Crystallogr. Sec. A 39, 813-817.

18. Wang, B.-C. (1985) Methods Enzymol. 115, 90-112.

19. Furey, W. \& Swaminathan, S. (1990) Am. Crystallogr. Assoc. Meeting Abstr. Ser. 2 18, 33-73.

20. Bricogne, G. (1976) Acta Crystallogr. Sec. A 32, 832-847.
21. Jones, T. A. (1978) Appl. Crystallogr. 11, 268-272.

22. Hendrickson, W. A. (1985) Methods Enzymol. 115, 252-271.

23. Smith, J. L., Corfield, P. W. R., Hendrickson, W. A. \& Low, B. W. (1988) Acta Crystallogr. Sec. A 44, 357-358.

24. Priestle, J. P. (1988) J. Appl. Crystallogr. 21, 572-576.

25. Connolly, M. L. (1983) J. Appl. Crystallogr. 16, 548-558.

26. Connolly, M. L. (1983) Science 221, 709-713.

27. Huheey, J. E. (1978) Inorganic Chemistry (Harper, New York), 2nd Ed.

28. Gee, N. S., Ragan, C. I., Watling, K. J., Aspley, S., Jackson, R. G., Reid, G. G., Gani; D. \& Shute, J. K. (1988) Biochem. J. 249, 883-889.

29. Diehl, R. E., Whiting, P., Potter, J., Gee, N., Ragan, C. I., Linmeyer, D., Schoepfer, R., Bennet, C. \& Dixon, R. A. F. (1990) J. Biol. Chem. 265, 5946-5949.

30. Ackermann, K. E., Gish, B. G., Honchar, M. P. \& Sherman, W. R. (1987) Biochem. J. 242, 517-524.

31. Shute, J. K., Baker, R., Billington, D. C. \& Gani, D. (1988) J. Chem. Soc., Chem. Commun., 626-628.

32. Baker, G. R. \& Gani, D. (1991) Bioorg. Med. Chem. Lett. 1, 193-196.

33. Ganzhorn, A. J. \& Chanal, M.-C. (1990) Biochemistry 29, 6065-6071.

34. Neuwald, A. F., York, J. D. \& Majerus, P. W. (1991) FEBS Lett. 294, 16-17.

35. Yano, R., Nagai, H., Shiba, K. \& Yura, T. (1990) J. Bacteriol. 172, 2124-2130.

36. Fabiny, J. M., Jayakumar, A., Chinault, A. C. \& Barnes, E. M., Jr. (1991) J. Gen. Microbiol. 137, 983-989.

37. Geever, R. F., Huiet, L., Baum, J. A., Tyler, B. M., Patel, V. B., Rutledge, B. J., Case, M. E. \& Giles, N. H. (1989) J. Mol. Biol. 207, 15-34.

38. Hawkins, A. R., Lamb, H. K., Smith, M., Keyete, J. W. \& Roberts, C. F. (1988) Mol. Gen. Genet. 214, 224-231.

39. Giles, N. H., Greever, R. F., Asch, D. K., Avalos, J. \& Case, M. E. (1991) J. Hered. 82, 1-7. 